\title{
First outbreak of Zika virus in the continental United States: a modelling analysis
}

G Marini ${ }^{1}$, G Guzzetta 2 , R Rosà 1 , S Merler 2

1. Department of Biodiversity and Molecular Ecology, Research and Innovation Centre, Fondazione Edmund Mach, San Michele all'Adige (Trento), Italy

2. Fondazione Bruno Kessler, Trento, Italy

Correspondence: Stefano Merler (merler@fbk.eu)

Since 2015, Zika virus (ZIKV) has spread throughout Latin and Central America. This emerging infectious disease has been causing considerable public health concern because of severe neurological complications, especially in newborns after congenital infections. In July 2016, the first outbreak in the continental United States was identified in the Wynwood neighbourhood of Miami-Dade County, Florida. In this work, we investigated transmission dynamics using a mathematical model calibrated to observed data on mosquito abundance and symptomatic human infections. We found that, although ZIKV transmission was detected in July 2016, the first importation may have occurred between March and mid-April. The estimated highest value for $R_{0}$ was 2.73 (95\% confidence interval $(\mathrm{Cl}): 1.65-4.17$ ); the attack rate was $14 \%$ (95\% Cl: 5.6-27.4\%), with 15 (95\% Cl: 6-29) pregnant women involved and a $12 \%$ probability of infected blood donations. Vector control avoided $60 \%$ of potential infections. According to our results, it is likely that further ZIKV outbreaks identified in other areas of Miami-Dade County were seeded by commuters to Wynwood rather than by additional importation from international travellers. Our study can help prepare future outbreak-related interventions in European areas where competent mosquitoes for ZIKV transmission are already established.

\section{Introduction}

Zika virus (ZIKV) has recently emerged as a significant threat to public health worldwide. Transmission of ZIKV to humans is thought to occur mainly via bites of Aedes aegypti mosquitoes; however, other mosquito species, such as Ae. albopictus, have been demonstrated as potential vectors $[1,2]$, and other routes of infection are possible, including sexual transmission [3], blood transfusion [4] and vertical transmission in both humans [5] and mosquitoes [6]. Although infection is usually asymptomatic or mild [7], a causal link with congenital birth defects has been established, and a strong association exists with Guillain-Barré syndrome
[8], a severe neurological condition. The low frequency of severe complications has been counterbalanced by a rapid geographic spread of the virus, which led the World Health Organization to declare a public health emergency of international concern (PHEIC) from 1 February to 18 November 2016. ZIKV was originally identified in Africa in 1947 [9], but the first large outbreak was not reported before 2007 in Micronesia [9], followed by further outbreaks in 2013 and 2014 in French Polynesia [10] and other Pacific Islands [7]. After the first cases were notified in Brazil in March 2015, ZIKV spread throughout South and Central America, with the notable exception of Uruguay and continental Chile, within 18 months $[11,43]$.

In Europe, locally transmitted cases of ZIKV have not occurred to date. Ae. aegypti is currently present only on Madeira (Portugal) and around the Black Sea [12]; the much more widespread Ae. albopictus has a similar competence for ZIKV at $27^{\circ} \mathrm{C}$, but none at $18{ }^{\circ} \mathrm{C}$ [2]. For these reasons, the risk of local transmission in temperate climate regions has been estimated to be minor $[13,14]$, but the possibility of outbreaks transmitted by Ae. albopictus cannot be ruled out in warmer areas, allowing both greater vector densities and higher competence. Indeed, $11 \%$ of the European population is estimated to live in areas suitable for a ZIKV epidemic, mostly concentrated in the Mediterranean basin [14].

In the continental United States (US), the first outbreak of ZIKV was recorded at the end of July 2016 in the Wynwood neighbourhood of Miami-Dade County, Florida [15]. In mid-August, mid-September and midOctober, three additional outbreaks in other areas of the same county (South Miami Beach, North Miami Beach and Little River) were identified. On 9 December 2016, the Florida Department of Health declared to have cleared active ZIKV transmission from all identified areas, which counted ca 250 locally acquired 
infections overall [16], and the area has been Zika-free since then.

In this work, we analysed the transmission dynamics of the Wynwood outbreak using a mathematical model calibrated to outbreak data, and we assessed the efficacy of the implemented vector control measures in containing viral transmission. Results from this analysis provide useful insights for prevention and control of possible future outbreaks in European areas.

\section{Methods}

The outbreak under study involved an area of approximately $2.6 \mathrm{~km} 2$ [15], with a population of 7,725 inhabitants [17]. Health authorities identified 21 locally transmitted symptomatic cases, with onset of illness ranging from 26 June to 5 August 2016.

We modelled the mosquito abundance over time $M(t)$ by considering a fixed mortality rate $\mu$ and a timedependent recruitment rate $\psi(t)$ (defined as the average number of adult female mosquitoes produced by a single female adult) previously estimated on $A e$. aegypti populations from Miami [18]. A density D of ca 1,560 female mosquitoes per hectare was estimated on $\bar{t}=26$ July, before vector control treatments [15], in the following equation, using parameter values reported in Table 1: $\mathrm{D}=$ K/anr2.

We modelled the mosquito abundance over time $M(t)$ by considering a fixed mortality rate $\mu \mathrm{M}$, a time-dependent recruitment rate $\psi(t)$ previously estimated on $A e$. aegypti populations from Miami [18] and their density $D$. Specifically, we applied the following system to compute the mosquito abundance on each day $t$ :

$$
\begin{aligned}
& M(t)^{\prime}=\psi(t) M(t)-\mu_{M} M(t) \\
& M(\bar{t})=D
\end{aligned}
$$

We modelled the interventions by imposing a sudden decrease of the mosquito population size by $\rho=75 \%$ after 6 August, as suggested by the entomological data presented in [15] (Figure 1, panel A).

Transmission dynamics of ZIKV in humans and mosquitoes were modelled according to the compartmental scheme reported in Figure 1, panel B. Susceptible humans $(S)$ contract ZIKV from bites of infectious mosquitoes. A fraction $q$ of infected individuals will remain asymptomatic $(A)$ for the entire duration of viraemic infection $t_{i}$, after which they will recover $(R)$; the remaining fraction $(1-q)$ will remain temporarily asymptomatic ( $I$ ) before developing symptoms $(C)$ and will then recover $(R)$. Recovered individuals are no longer infectious and become immune to reinfections. We assumed that infected humans $\left(H_{j}\right)$ are infectious regardless of apparent clinical symptoms. Symptomatic individuals have an overall probability $d$ of being detected at some point. Susceptible mosquitoes $\left(M_{s}\right)$ can become infected $\left(M_{e}\right)$ after biting infectious humans; in such cases, they will become infectious to humans $(M i)$ after an extrinsic incubation period and for the rest of their life. Given the very small rates of vertical transmission [6], we assumed that all mosquitoes newly emerged from their breeding site are susceptible.

To take into account the uncertainty surrounding the epidemiological parameters, we ran a stochastic version of the model proposed in Figure 1, panel B. We implemented an agent-based model representing the 7,725 inhabitants of the Wynwood neighbourhood, following an approach similar to the one presented in [19]. On each day, susceptible humans move to the infectious compartments based on a Poisson sample with a rate equal to the force of infection $\lambda_{H}$; infected humans are subject to a binomial probability $q$ of remaining asymptomatic. Asymptomatic individuals will remain infectious for a time $t$, sampled from a uniform distribution with a range of 7-13 days; symptomatic individuals will show their symptoms after a time $L_{H}$ drawn from a gamma distribution with a mean of 5.9 days and shape parameter 0.5. Symptoms will last until recovery for a time $\mathrm{aH}$, sampled from a normal distribution with a mean of 4.5 days and standard deviation 0.75 . Vector dynamics were implemented as a stochastic stage-structured model representing the three possible epidemiological stages of the vector: susceptible, exposed and infected. See Table 1 for details on model parameters and the corresponding references for the adopted probability distributions.

We assumed that the Wynwood outbreak was initiated by a single index case imported in the area via international travel at time $T_{0}$. Two free model parameters ( $T_{0}$ and the mosquito biting rate $b$ ) were estimated by fitting the model-predicted weekly number of reported symptomatic cases to the observed cases. We used a Markov chain Monte Carlo (MCMC) approach with a standard Metropolis-Hastings algorithm with 100,000 iterations, uniform priors (range for $\mathrm{T}_{0}: 1$ January-20 June; range for $b$ : $0-1$ ) and a Poisson likelihood. We used the parameter values accepted by the algorithm as the posterior distributions, which were used to compute model predictions.

We computed the initial reproduction number Ro(t) from the following formula [20]:

$R_{0}(t)=\frac{b^{2} \cdot p_{H M} \cdot p_{H M}}{\mu_{M} \cdot t_{i}} \cdot \frac{M(t)}{H} \cdot \frac{\theta M}{\theta_{M}+\mu_{M}}$,

using the posterior distribution of the mosquito biting rate $b$, the modelled mosquito abundance $M(t)$ and the epidemiological parameter values for ZIKV (Table 1). $R_{o}(\mathrm{t})$ represents a measure of the invasion potential of an infectious host introduced in a fully susceptible host population on day $t$. We also computed the effective reproduction number $R_{e}(\mathrm{t})$ as the product of $R_{o}(\mathrm{t})$ and the fraction of available susceptible individuals in the population [21]. $R_{e}(\mathrm{t})$ represents the residual transmission potential of an epidemic as the reservoir of 
Modelled mosquito abundance and transmission model for Zika virus outbreak, Wynwood, 2016

A.

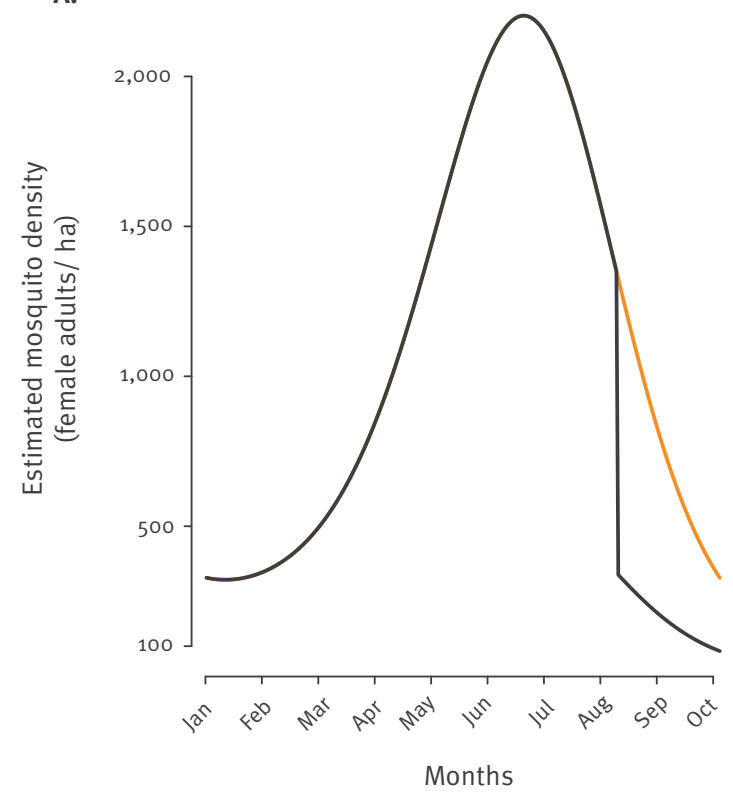

B.

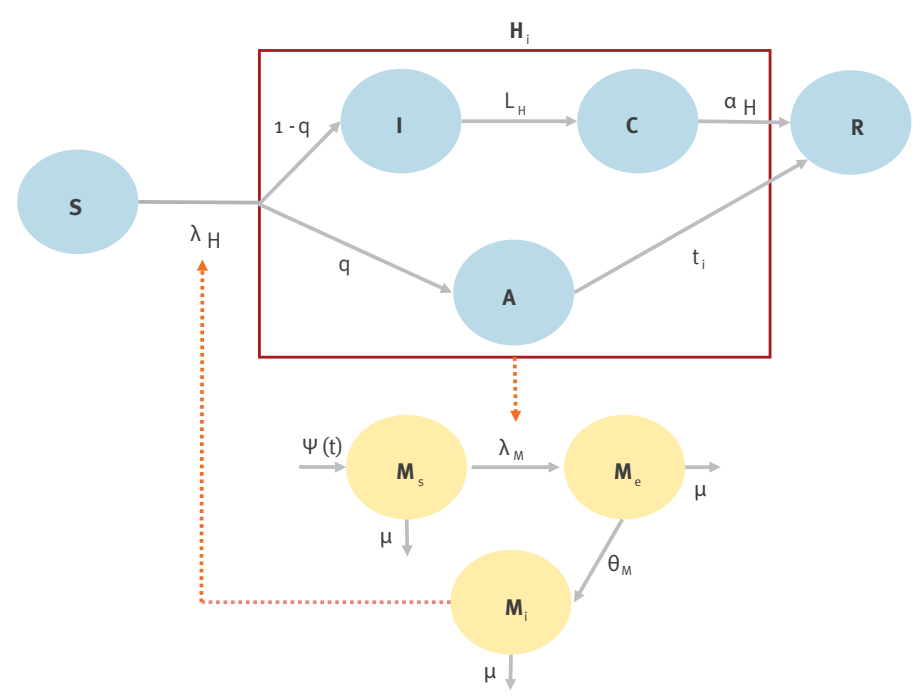

A. Predicted mosquito abundance over time in the study area. Black: $75 \%$ reduction in mosquito abundance following 6 August due to vector control interventions; orange: no vector control implemented.

B. Model flow chart for ZIKV transmission in humans (blue) and mosquitoes (yellow). Compartments: A: permanently asymptomatic humans; I: asymptomatic humans who will develop symptoms; $C$ : symptomatic humans; $M_{e}$ : exposed mosquitoes; $M_{i}$ : infectious mosquitoes; $M_{s}$ : susceptible mosquitoes; R: humans who recovered after symptoms; S: susceptible humans. Parameters: $\lambda_{H}$ and $\lambda_{M}$ are the force of infection for humans and mosquitoes respectively and are computed as $\lambda_{H}=b p_{M H} M_{i} / H$ and $\lambda_{M}=b p_{H M} H_{i} / H$, with $H$ being the total human population in Wynwood; $\Psi(t)$ is the mosquito recruitment rate, given by $\Psi(t)=\psi(t)\left(M_{s}+M_{e}+M_{i}\right)$. See Table 1 for parameter values and references.

susceptible individuals is depleted by the process of infection and recovery.

We also estimated the number of infected pregnant women and blood donors based on the model-predicted prevalence of human infections over time. Data on fertility [17] and blood donation [22] rates by age and ethnicity were adapted to the demographic structure of Miami-Dade County [17]. We considered all blood donations occurring between $T_{0}$ and 27 July, when health authorities suspended blood collection from the area [23].

We evaluated the robustness of the proposed model ('baseline model') by fitting alternative model structures after varying some of the key assumptions: (i) We considered a broader mosquito flight range $r$ of $82.5 \mathrm{~m} \mathrm{[24]} \mathrm{in} \mathrm{the} \mathrm{estimation} \mathrm{of} \mathrm{the} \mathrm{mosquito} \mathrm{abun-}$ dance (model $\mathrm{M}_{1}$ ); (ii) we assumed a relative reduction in mosquito abundance due to the vector control treatments $(\rho)$ as a free model parameter sampled with a uniform prior with a range of $0-100 \%$ (model $\mathrm{M}_{2}$ ); (iii) we let the mosquito biting rate $b$ vary over time, according to the same temporal dependence assumed for the recruitment rate [18] (model $\mathrm{M}_{3}$ ); (iv) we evaluated a model where the reporting rate $d$ was a free model parameter with a uniform prior of 0-100\% (model $\mathrm{M}_{4}$ ). Models were ranked according to the deviance information criterion (DIC) [25].

\section{Results}

The baseline model was able to reproduce the number of cases by date of symptom onset (Figure 2, panel A), as reported by health authorities [15]. The arrival of the index case was estimated between early March and mid-April (average: 18 March; 95\% confidence interval (CI): 1 March-15 April), approximately corresponding to the dates when $\mathrm{R}_{0}(\mathrm{t})$ approached the epidemic threshold (average: 28 March; 95\% Cl: 8 March-22 April). We estimated $\mathrm{R}_{0}$ to vary from a minimum of $0.4(95 \% \mathrm{Cl}$ : $0.24-0.61)$ during winter to a maximum of 2.73 (95\% $\mathrm{Cl}: 1.65-4.17)$ in mid-June (Figure 2, panel B).

The total estimated number of human infections was 1,112 (95\% Cl: 436-2,120), corresponding to an average attack rate of $14.4 \%$ (95\% Cl: 5.6-27.4\%). We estimated 15 (95\% Cl: 6-29) pregnant women to have been infected during the outbreak and a probability of $12 \%$ that at least one infectious individual donated blood before 27 July. The low occurrence of viraemic blood donors is due to smaller donation rates among the Hispanic population [22], the main ethnicity in 


\section{FIGURE 2}

Reported cases, Ro, and viral prevalence in humans as predicted by the model for Zika virus outbreak, Wynwood, 2016

A.

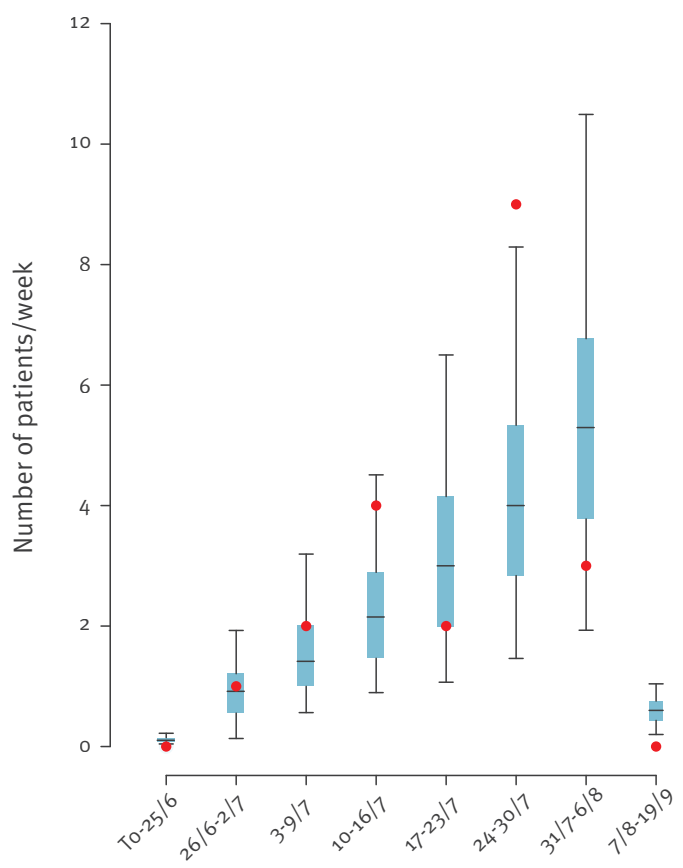

Period of symptoms onset

C.

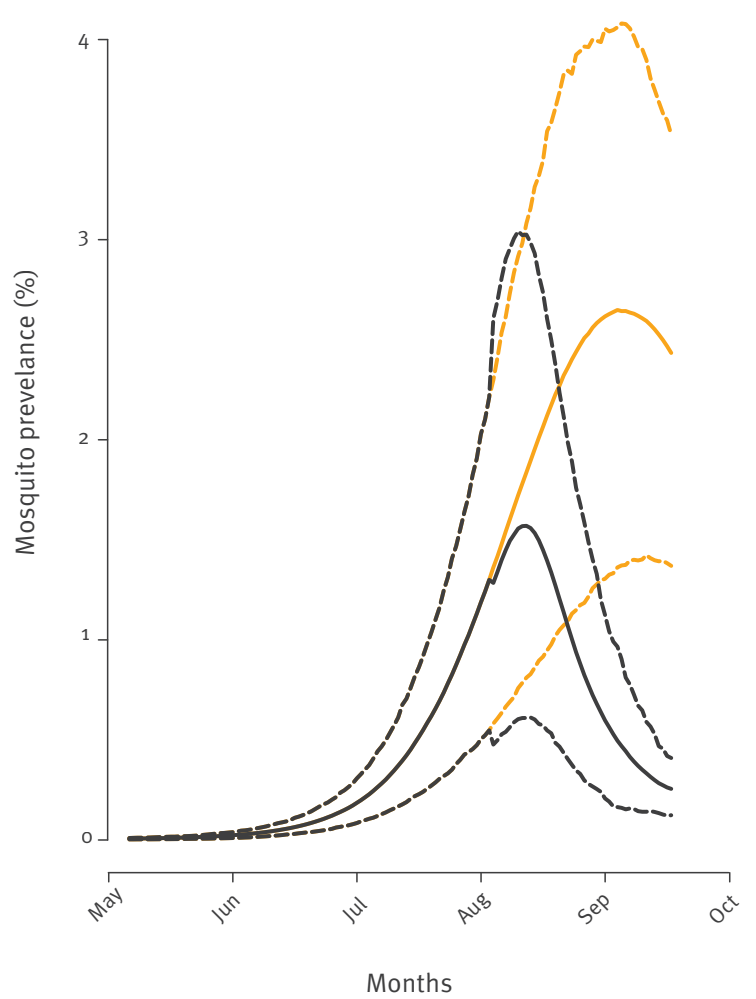

B.

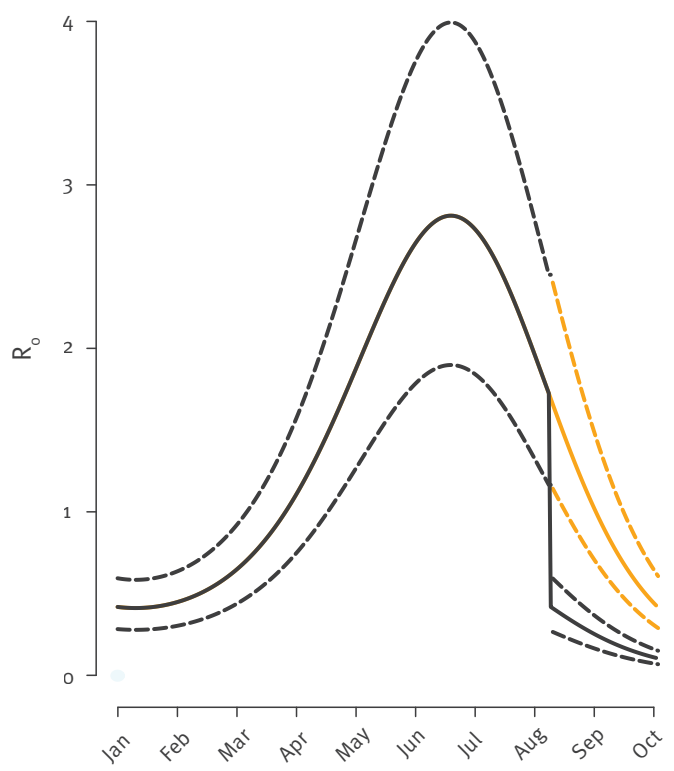

Months

D.

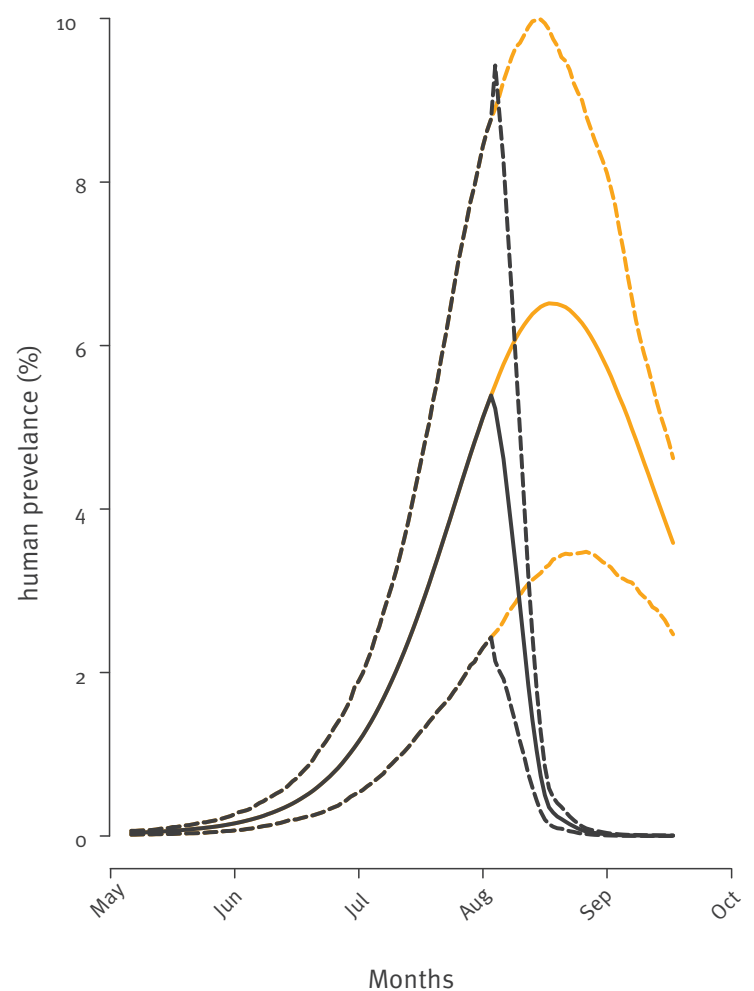

A. Predicted weekly number of reported symptomatic cases by date of symptom onset. Red dots represent observations [15] whereas boxplots indicate quantiles of the corresponding model-predicted distribution at $2.5 \%, 25 \%, 50 \% 75 \%$ and $97.5 \%$.

B. Model estimates of the initial reproductive number for ZIKV in Wynwood over time.

C. Model-predicted prevalence of ZIKV in mosquitoes.

D. Model-predicted prevalence of ZIKV in human hosts.

Solid lines: mean values; dashed lines: $95 \%$ confidence interval; black: $75 \%$ reduction in mosquito abundance following 6 August due to vector control interventions; orange: no vector control implemented. 
TABLE 1

Model parameters for Zika virus outbreak, Wynwood, 2016

\begin{tabular}{|c|c|c|c|}
\hline Parameter & Interpretation & Value & Source \\
\hline$K$ & Female mosquitoes per trap per day before interventions & 30 & [15] \\
\hline$a$ & Capture rate (\%/day) & 2.46 & [40] \\
\hline$r$ & Flight range for Aedes aegypti (in m) & 50 & [41] \\
\hline$\rho$ & Reduction in mosquito abundance following treatments (\%) & 75 & [15] \\
\hline$p_{M H}$ & Probability of transmission from mosquito to human per bite & 0.214 & [1] \\
\hline$p_{\text {HM }}$ & Probability of transmission from human to mosquito per bite & 0.767 & [1] \\
\hline$\theta_{M}$ & Mosquito incubation period (days) & $\begin{array}{l}\text { Gamma distribution } \\
(\mu=10.5, \sigma=0.5)\end{array}$ & [19] \\
\hline$L_{H}$ & Latency before symptom development (days) & $\begin{array}{l}\text { Gamma distribution } \\
(\mu=5.9, \sigma=0.5)\end{array}$ & [19] \\
\hline$a_{H}$ & Symptomatic period (days) & $\begin{array}{l}\text { Normal distribution } \\
(\mu=4.5, \sigma=0.75)\end{array}$ & [19] \\
\hline$t_{i}$ & Duration of asymptomatic infection (days) & $\begin{array}{c}\text { Uniform } \\
\text { (range 7-13) }\end{array}$ & [42] \\
\hline 9 & Probability of being asymptomatic & 0.8 & {$[4,7]$} \\
\hline$\mu_{M}$ & Ae. aegypti death rate (1/days) & 0.1 & [18] \\
\hline$\psi(t)$ & Ae. aegypti recruitment rate ( 1 /days) & $\mu_{M}(1+0.25 \cos (2 \pi / 365(t-90.89))$ & [18] \\
\hline$d$ & Reporting probability for symptomatic individuals & 0.1 & [19] \\
\hline$T_{o}$ & Date of index case importation & $\begin{array}{c}18 \text { March } \\
(95 \% \mathrm{Cl}: 1 \text { March-15 April) }\end{array}$ & Calibrated \\
\hline$b$ & Mosquito biting rate (1/days) & $\begin{array}{c}0.058 \\
(95 \% \mathrm{Cl}: 0.055-0.061)\end{array}$ & Calibrated \\
\hline
\end{tabular}

$\mathrm{Cl}$ : confidence interval.

\section{TABLE 2}

Effectiveness of alternative scenarios of vector control interventions on Zika virus infections, Wynwood, 2016

\begin{tabular}{|c|c|c|c|c|c|}
\hline \multirow{2}{*}{$\begin{array}{l}\text { Reduction of mosquito } \\
\text { abundance (6 August) }\end{array}$} & \multicolumn{2}{|c|}{$\begin{array}{c}\text { Total number of reported symptomatic } \\
\text { cases }\end{array}$} & \multicolumn{2}{|c|}{ Total attack rate } & \multirow{2}{*}{$\begin{array}{c}\text { Fraction of prevented infections } \\
\text { compared with no intervention } \\
\%\end{array}$} \\
\hline & $\mathrm{n}$ & $95 \% \mathrm{Cl}$ & $\%$ & $95 \% \mathrm{Cl}$ & \\
\hline $0 \%$ (no intervention) & 55 & $29.5-81.7$ & 33.0 & $16.7-49.3$ & 0 \\
\hline $25 \%$ & 33.7 & $17.1-57.8$ & 21.4 & $10.9-37.4$ & 35.1 \\
\hline $50 \%$ & 26.5 & $11.4-48.8$ & 17.0 & $6.2-31.7$ & 51.5 \\
\hline $75 \%$ & 22.6 & $9.2-42.2$ & 14.4 & $5.6-27.4$ & 56.4 \\
\hline $90 \%$ & 21.3 & $9.7-35.8$ & 11.7 & $5.4-20.3$ & 64.5 \\
\hline $75 \%^{a}$ & 18.1 & $9.2-33.2$ & 11.5 & $5.9-20.8$ & 65.1 \\
\hline
\end{tabular}

$\mathrm{Cl}$ : confidence interval.

The assumed effectiveness of implemented measures is shown in bold.

${ }^{a}$ Reduction of mosquito abundance occurring on the same day of outbreak detection (23 July).

Miami-Dade [17], and to the low («4\%) predicted ZIKV prevalence until July.

According to data from the American Community Survey [26], incoming commuters represent ca $44 \%$ of the Miami-Dade population; of this proportion, the large majority $(87 \%)$ are within-county commuters, while $13 \%$ come from outside the county (mostly from the neighbouring Broward County). This would correspond to ca $5.7 \%$ of infections ( $13 \%$ of $44 \%$ ), i.e. ca 1 in 18 , in commuters from outside the county and indeed, one of the 21 symptomatic patients reported in the outbreak was a commuter from Broward County identified via workplace investigation [15]. About 453 infections occurred in commuters resident in other parts of Miami-Dade; for comparison, only 208 travelrelated ZIKV cases were recorded in Miami-Dade as of 19 September [27].

Vector control strategies were crucial for containing virus circulation by rapidly abating the average value of $R_{e}$ from 1.49 to 0.37 , with a sharp reduction of infection prevalence in both vectors and humans (Figure 2, panels $C$ and $D$ ). In the absence of interventions, the 
TABLE 3

Comparison between alternative models, Zika virus outbreak, Wynwood, 2016

\begin{tabular}{|c|c|c|c|c|c|c|c|c|c|c|c|}
\hline \multirow[t]{2}{*}{ Model } & \multirow[t]{2}{*}{ DIC } & \multicolumn{2}{|c|}{ Average $\mathrm{T}_{0}$} & \multicolumn{2}{|c|}{ Average $b$} & \multicolumn{2}{|c|}{$\begin{array}{l}\text { Average } \\
\text { attack rate }\end{array}$} & \multicolumn{2}{|c|}{ Average $d$} & \multicolumn{2}{|c|}{ Average $\rho$} \\
\hline & & Date & $95 \% \mathrm{Cl}$ & Days $^{-1}$ & $95 \% \mathrm{Cl}$ & $\%$ & $95 \% \mathrm{Cl}$ & $\%$ & $95 \% \mathrm{Cl}$ & $\%$ & $95 \% \mathrm{Cl}$ \\
\hline Mo: baseline model & 36.55 & $18 \mathrm{Mar}$ & $1 \mathrm{Mar}-15 \mathrm{Apr}$ & 0.05 & $\begin{array}{c}0.055^{-} \\
0.061\end{array}$ & 14.4 & $5.6-27.4$ & NA & NA & NA & NA \\
\hline $\begin{array}{l}\text { M1: model with } \\
\text { increased flight } \\
\text { range }\end{array}$ & 36.84 & $20 \mathrm{Feb}$ & $\begin{array}{l}23 \operatorname{Jan}-24 \\
\text { Mar }\end{array}$ & 0.093 & $\begin{array}{l}0.088- \\
0.100\end{array}$ & 17.4 & $4.1-36.6$ & NA & NA & NA & NA \\
\hline $\begin{array}{l}\text { M2: model with } \\
\text { free vector control } \\
\text { efficacy }\end{array}$ & 36.92 & $16 \mathrm{Feb}$ & $\begin{array}{l}21 \mathrm{Jan}-21 \\
\text { Mar }\end{array}$ & 0.058 & $\begin{array}{l}0.054^{-} \\
0.061\end{array}$ & $15 \cdot 3$ & $4.2-28.0$ & NA & NA & 85.4 & $60.1-99.9$ \\
\hline $\begin{array}{l}\text { M3: model with time- } \\
\text { dependent biting } \\
\text { rate }\end{array}$ & 37.20 & 13 Feb & $\begin{array}{c}1 \mathrm{Feb}-21 \\
\text { Mar }\end{array}$ & 0.052 & $\begin{array}{l}0.049- \\
0.055\end{array}$ & 16.9 & $4.2-35.7$ & NA & NA & $N A$ & NA \\
\hline $\begin{array}{l}\text { M4: model with free } \\
\text { reporting rate }\end{array}$ & 39.15 & $10 \mathrm{Mar}$ & $\begin{array}{c}10 \mathrm{Feb}-3 \\
\mathrm{Apr}\end{array}$ & 0.057 & $\begin{array}{l}0.054^{-} \\
0.060\end{array}$ & 15.0 & $4.2-27.3$ & 12.8 & $10.0-19.7$ & NA & NA \\
\hline
\end{tabular}

$\mathrm{CI}$ : confidence interval; DIC: deviance information criterion; NA: not applicable.

model suggested that $R_{e}$ would have remained above the critical threshold until the end of August, resulting in $55(95 \% \mathrm{Cl}: 29.5-81.7)$ reported symptomatic infections and a total attack rate of $33 \%$ ( $95 \% \mathrm{Cl}: 16.7-49.3)$. Thus, according to our model, the implemented interventions have prevented ca $60 \%$ of all potential cases. Table 2 shows a sensitivity analysis of the expected total number of reported symptomatic cases, attack rate, and fraction of prevented infections for alternative scenarios on the assumed reduction in mosquito abundance allowed by the interventions. We estimated that even a treatment with low effectiveness, corresponding to a reduction of $25 \%$ of the vector population, would significantly reduce the expected number of infections by almost 40\%.

Table 3 shows a summary of results obtained with alternative assumptions on the model structure and parameter values. While the baseline model had the best performance in terms of DIC score, the overall qualitative conclusions were robust with respect to these variations, with alternative models suggesting an even earlier introduction of the virus and a slightly higher attack rate. The assumptions of $\rho=75 \%$ and $d=10 \%$ for the baseline model Mo were compliant with the estimates computed for models $M_{2}$ and $M_{4}$, respectively, where these parameters were estimated through the MCMC procedure.

\section{Discussion}

In this work, we estimated that ZIKV was introduced to Wynwood between 3 and 5 months before the recognition of the outbreak by health authorities at the end of July. This long delay is justified because the infection prevalence in humans was small until June and because ZIKV symptomaticity [28] and reporting rates were low [19]. Our conclusion is supported by molecular-clock analyses of 32 ZIKV isolates from Florida, reported by the collaborative project nextstrain [29,30], which suggest that importation occurred between the end of February and the end of March. Model simulations indicate a likely extinction of transmission during winter even in the absence of interventions; however, we propose that undetected infections have occurred even after authorities declared the end of the outbreak on 19 September [27], given the sustained presence of infected mosquitoes. This prediction is consistent with the identification of locally transmitted cases in MiamiDade as late as 28 December, almost three weeks after all active outbreaks in the area had been declared over [31]. Finally, our results suggest that the other three outbreaks in neighbouring areas of Miami-Dade County were probably seeded from Wynwood commuters rather than initiated from travel-related cases; a phylogenetic analysis of ZIKV isolates [29] supports this finding and shows that at most two viral clades were circulating in the four Florida outbreaks in 2016.

Our estimate of the mosquito biting rate is in line with a recent study that found parity and blood meal frequency to increase with temperature [32]. In particular, $60 \%$ of female mosquitoes were parous at $24^{\circ} \mathrm{C}$ and took blood meals at an average interval of 11.7 days, whereas a parity of $86 \%$ and an interval between blood meals of 9.8 days were found at $27^{\circ} \mathrm{C}$. These figures correspond to a rate between 0.051 and 0.088 bites per mosquito per day. We estimated an average biting rate of 0.058 per mosquito per day throughout the period March to September, when the average temperature in Miami is $26.1^{\circ} \mathrm{C}$ [33]. Because data on the biting rate at lower temperatures was not available, we did not include its temperature dependence as a possible driver of temporal variations in the transmission risk; however, the model assuming a seasonal dependency in the biting rate resulted in a similar quality of fit, an earlier estimated date of importation and a slightly 
higher attack rate. Other model parameters may be influenced by seasonal variations in temperature, with possibly shorter incubation periods (as in the case of dengue [34]) and increased transmission rates [2] during warmer months. Data for natural history parameters of ZIKV are insufficient to factor the temperature dependence in our model. Nonetheless, by analogy to what we found for the time-dependent biting rate, we expect that a further concentration of transmission in summer months would increase the estimated attack rate and push further back the date of introduction.

We estimated a peak value for $R_{o}$ of ca 2.7 , well within the range of other estimates for outbreaks in the Pacific and the Americas $[14,19,35]$. Previously published predictions for European areas with endemic Ae. albopictus populations also suggest potential values for Ro below 3 in the large majority of sites [14]. Therefore, the Wynwood outbreak is a relevant case study for potential future ZIKV transmission in Europe and can provide useful insights for prevention and control.

In Wynwood, about two weeks elapsed between recognition of local transmission on 23 July and a massive reduction in captured mosquitoes on 6 August [15]. These timely measures were successful in containing the attack rate below $15 \%$. Even if effective interventions were immediately deployed on the day when local transmission was detected, the attack rate would still be above $11 \%$. Because ZIKV is transmitted in a population for a long time before detection, reactive control measures are insufficient to prevent a large number of infections. A more effective approach would require the application of preventive measures with the aim of keeping $R_{0}$ below the epidemic threshold. A recent study conducted on European Ae. albopictus showed that integrated vector control strategies can halve the mosquito abundance (and therefore $\mathrm{R}_{\mathrm{o}}$ ) compared with sites where no intervention is implemented [36]. This reduction would not be sufficient to completely eliminate the risk of local transmission in the most exposed areas, but it would greatly limit the time window over which an epidemic is possible and, most importantly, its potential size, thereby reducing the risk of seeding further outbreaks in neighbouring areas. Furthermore, preventive control of mosquito populations would simultaneously reduce the risks of other mosquitoborne infections such as chikungunya and dengue [37].

Our conclusions are subject to some unknowns on ZIKV epidemiology, such as the role of asymptomatic infections, sexual transmission and spatial dynamics, along with uncertainties in parameter values and possible drifts in vector competence following adaptations of the viral genome [38]. The implications of this study for control are expected to be robust with respect to these uncertainties, since they depend on the silent transmission of ZIKV in the early months after importation, which is now a well-established trait of this emerging infection [39].
Acknowledgements

This work was supported by the European Union's Horizon 2020 Research and Innovation Programme under ZIKAlliance Grant Agreement no. 734548.

\section{Conflict of interest}

None declared.

Authors' contributions

GM, GG, RR and SM conceived the study. GM and GG performed the analysis and drafted the manuscript. All authors contributed to interpretation of the results, as well as read and approved the final version of the manuscript.

\section{References}

1. Chouin-Carneiro T, Vega-Rua A, Vazeille M, Yebakima A, Girod $\mathrm{R}$, Goindin D, et al. Differential susceptibilities of Aedes aegypti and Aedes albopictus from the Americas to Zika virus. PLoS Negl Trop Dis. 2016;10(3):eooo4543. DOI: 10.1371/ journal.pntd.0004543 PMID: 26938868

2. Heitmann A, Jansen $S$, Lühken R, Leggewie $M$, Badusche $M$, Pluskota B, et al. Experimental transmission of Zika virus by mosquitoes from central Europe. Euro Surveill. 2017;22(2):30437. DOI: 10.2807/1560-7917.ES.2017.22.2.30437 PMID: 28106528

3. Mansuy JM, Dutertre M, Mengelle C, Fourcade C, Marchou $B$, Delobel $P$, et al. Zika virus: high infectious viral load in semen, a new sexually transmitted pathogen? Lancet Infect Dis. 2016;16(4):405. DOI: 10.1016/S1473-3099(16)00138-9 PMID: 26949027

4. Musso D, Nhan T, Robin E, Roche C, Bierlaire D, Zisou $\mathrm{K}$, et al. Potential for Zika virus transmission through blood transfusion demonstrated during an outbreak in French Polynesia, November 2013 to February 2014. Euro Surveill. 2014;19(14):20761. DOI: 10.2807/1560-7917. ES2014.19.14.20761 PMID: 24739982

5. Besnard M, Lastere S, Teissier A, Cao-Lormeau V, Musso D. Evidence of perinatal transmission of Zika virus, French Polynesia, December 2013 and February 2014. Euro Surveill. 2014;19(13):20751. DOI: 10.2807/1560-7917.ES2014.19.13.20751 PMID: 24721538

6. Thangamani S, Huang J, Hart CE, Guzman H, Tesh RB. Vertical transmission of Zika virus in Aedes aegypti mosquitoes. Am J Trop Med Hyg. 2016;95(5):1169-73. DOI: 10.4269/ ajtmh.16-0448 PMID: 27573623

7. Duffy MR, Chen T-H, Hancock WT, Powers AM, Kool JL, Lanciott RS, et al. Zika virus outbreak on Yap Island, Federated States of Micronesia. N Engl J Med. 2009;360(24):2536-43. DOI: 10.1056/NEJMoao805715 PMID: 19516034

8. Krauer F, Riesen M, Reveiz L, Oladapo OT, Martínez-Vega R, Porgo TV, et al. , WHO Zika Causality Working Group. Zika virus infection as a cause of congenital brain abnormalities and Guillain-Barré syndrome: systematic review.PLoS Med. 2017;14(1):e1002203. DOI: 10.1371/journal.pmed.1002203 PMID: 28045901

9. Hayes EB. Zika virus outside Africa.Emerg Infect Dis. 2009;15(9):1347-50. DOI: 10.3201/eid1509.090442 PMID: 19788800

10. Oehler E, Watrin L, Larre P, Leparc-Goffart I, Lastere S, Valour $\mathrm{F}$, et al. Zika virus infection complicated by Guillain-Barre syndrome--case report, French Polynesia, December 2013. Euro Surveill. 2014;19(9):20720. DOI: 10.2807/1560-7917. ES2014.19.9.20720 PMID: 24626205

11. World Health Organization (WHO). New detection of mosquitoborne Zika virus infections, 2013 - 2016. Geneva: WHO. [Accessed: 13 Mar 2017]. Available from: http://www.who.int/ emergencies/zika-virus/situation-report/zika-timeline-13october-2016.png?ua=1

12. Kraemer MU, Sinka ME, Duda KA, Mylne AQ, Sheare $\mathrm{FM}$, Barker CM, et al. The global distribution of the 
arbovirus vectors Aedes aegypti and Ae. albopictus. eLife. 2015;4:e08347. DOI: 10.7554/eLife.08347 PMID: 26126267

13. Guzzetta G, Poletti P, Montarsi F, Baldacchino F, Capelli G, Rizzoli A, et al. Assessing the potential risk of Zika virus epidemics in temperate areas with established Aedes albopictus populations. Euro Surveill. 2016;21(15):30199. DOI: 10.2807/1560-7917.ES.2016.21.15.30199 PMID: 27104366

14. Rocklöv J, Quam MB, Sudre B, German M, Kraemer MU, Brady 0 , et al. Assessing seasonal risks for the introduction and mosquito-borne spread of Zika virus in Europe. EBioMedicine. 2016;9:250-6. DOI: 10.1016/j.ebiom.2016.06.009 PMID: 27344225

15. Likos A, Griffin I, Bingham AM, Stanek D, Fischer M, White $S$, et al. Local Mosquito-Borne Transmission of Zika Virus - Miami-Dade and Broward Counties, Florida, June-August 2016. MMWR Morb Mortal Wkly Rep. 2016;65(38):1032-8. DOI: 10.15585/mmwr.mm6538e1 PMID: 27684886

16. Florida Department of Health (DOH). Department of Health daily Zika update. Tallahassee: DOH; 9 Dec 2016. Available from: http://www.floridahealth.gov/ newsroom/2016/12/120916-zika-update.html

17. US Census 2010. Washington: United States Census Bureau. [Accessed: 13 Mar 2017]. Available from: http://www.census. gov/2010census/

18. Robert MA, Christofferson RC, Silva NJB, Vasquez C, Mores $\mathrm{CN}$, Wearing $\mathrm{HJ}$. Modeling mosquito-borne disease spread in U.S. urbanized areas: the case of dengue in Miami.PLoS One. 2016;11(8):e0161365. DOI: 10.1371/journal.pone.0161365 PMID: 27532496

19. Kucharski AJ, Funk S, Eggo RM, Mallet H-P, Edmunds WJ, Nilles EJ. Transmission dynamics of Zika virus in island populations: a modelling analysis of the 2013-14 French Polynesia outbreak. PLoS Negl Trop Dis. 2016;10(5):eoo04726. DOI: 10.1371/ journal.pntd.0004726 PMID: 27186984

20. Manore CA, Hickmann KS, Xu S, Wearing HJ, Hyman JM. Comparing dengue and chikungunya emergence and endemic transmission in A. aegypti and A. albopictus.J Theor Biol. 2014;356:174-91. DOI: 10.1016/j.jtbi.2014.04.033 PMID: 24801860

21. Keeling M, Rohani P. Modeling infectious diseases in humans and animals. Princeton: Princeton University Press; 2008.

22. Shaz BH, James AB, Hillyer KL, Schreiber GB, Hillyer CD. Demographic patterns of blood donors and donations in a large metropolitan area.J Natl Med Assoc. 2011;103(4):351-7. DOI: 10.1016/So027-9684(15)30316-3 PMID: 21805814

23. Florida Department of Health (DOH). Department of Health daily Zika update. Tallahassee: DOH; 29 Jul 2016. Available from: http://www.floridahealth.gov/ newsroom/2016/07/072916-local-zika.html

24. David MR, Lourenço-de-Oliveira R, Freitas RM. Containe productivity, daily survival rates and dispersal of Aedes aegypti mosquitoes in a high income dengue epidemic neighbourhood of Rio de Janeiro: presumed influence of differential urban structure on mosquito biology.Mem Inst Oswaldo Cruz. 2009;104(6):927-32. DOI: 10.1590/So07402762009000600019 PMID: 19876569

25. Spiegelhalter DJ, Best NG, Carlin BP, van der Linde A. Bayesian measures of model complexity and fit.J R Stat Soc B. 2002;64(4):583-639. DOI: 10.1111/1467-9868.00353

26. County to county commuting flows for the United States and Puerto Rico: 2009-2013. Commuting flows. Table 1. Washington: United States Census Bureau; 20 Apr 2017. Available from: https://www2.census.gov/programs-surveys/ commuting/tables/time-series/commuting-flows

27. Florida Department of Health (DOH). Department of Health daily Zika update. Tallahassee: DOH; 19 Sept 2016. Available from: http://www.floridahealth.gov/ newsroom/2016/09/091916-zika-update.htm

28. Lessler J, Chaisson LH, Kucirka LM, Bi Q, Grantz K, Salje H, et al. Assessing the global threat from Zika virus. Science. 2016;353(6300):aaf8160. DOI: 10.1126/science.aaf8160 PMID: 27417495

29. Nextstrain. Real-time tracking of Zika virus evolution. [Accessed 13 Mar 2017]. Available from: http://www.nextstrain. org/zika/

30. Neher RA, Bedford T. nextflu: real-time tracking of seasonal influenza virus evolution in humans.Bioinformatics. 2015;31(21):3546-8. DOI: 10.1093/bioinformatics/btv381 PMID: 26115986

31. Florida Department of Health (DOH). Department of Health daily Zika update. Tallahassee: DOH; 28 Dec 2016. Available from: http://www.floridahealth.gov/ newsroom/2016/12/122816-zika-update.html

32. Goindin D, Delannay C, Ramdini C, Gustave J, Fouque F. Parity and longevity of Aedes aegypti according to temperatures in controlled conditions and consequences on dengue transmission risks.PLoS One. 2015;10(8):e0135489. DOI: 10.1371/journal.pone.0135489 PMID: 26258684

33. National Weather Service Forecast Office. Miami-South Florida. Silver Spring: National Oceanic and Atmospheric Administration. [Accessed 13 Mar 2017]. Available from: https://www.weather.gov/climate/index.php?wfo=mfl

34. Focks DA, Haile DG, Daniels E, Mount GA. Dynamic life table model for Aedes aegypti (diptera: Culicidae): simulation results and validation.J Med Entomol. 1993;30(6):1018-28. DOI: 10.1093/jmedent/30.6.1018 PMID: 8271243

35. Nishiura H, Mizumoto K, Villamil-Gómez WE, RodríguezMorales AJ. Preliminary estimation of the basic reproduction number of Zika virus infection during Colombia epidemic, 20152016.Travel Med Infect Dis. 2016;14(3):274-6. DOI: 10.1016/j. tmaid.2016.03.016 PMID: 27060613

36. Baldacchino F, Bussola F, Arnoldi D, Marcantonio M, Montarsi F, Capelli G, et al. An integrated pest control strategy against the Asian tiger mosquito in northern Italy: a case study. Pest Manag Sci. 2017;73(1):87-93. DOI: 10.1002/ps.4417 PMID: 27539880

37. Guzzetta G, Poletti P, Montarsi F, Baldacchino F, Capelli G, Rizzoli A, et al. Assessing the potential risk of Zika virus epidemics in temperate areas with established Aedes albopictus populations. Euro Surveill. 2016;21(15):30199. DOI: 10.2807/1560-7917.ES.2016.21.15.30199 PMID: 27104366

38. Pettersson JH, Eldholm V, Seligman SJ, Lundkvist Å, Falconar AK, Gaunt MW, et al. How Did Zika Virus Emerge in the Pacific Islands and Latin America? MBio. 2016;7(5):e01239-16. DOI: 10.1128/mBio.01239-16 PMID: 27729507

39. Faria NR, Azevedo RDSDS, Kraemer MUG, Souza R, Cunha MS, Hill SC, et al. Zika virus in the Americas: Early epidemiological and genetic findings. Science. 2016;352(6283):345-9. DOI: 10.1126/science.aaf5036 PMID: 27013429

40. Maciel-de-Freitas R, Eiras AE, Lourenço-de-Oliveira R. Field evaluation of effectiveness of the BG-Sentinel, a new trap for capturing adult Aedes aegypti (Diptera: Culicidae).Mem Inst Oswaldo Cruz. 2006;101(3):321-5. DOI: 10.1590/So07402762006000300017 PMID: 16862330

41. Bergero PE, Ruggerio CA, Lombardo R, Schweigmann NJ, Solari HG. Dispersal of Aedes aegypti: field study in temperate areas using a novel method.J Vector Borne Dis. 2013;50(3):163-70. PMID: 24220074

42. Lessler J, Ott CT, Carcelen AC, Konikoff JM, Williamson J, $\mathrm{Bi}$, et al. Times to key events in Zika virus infection and implications for blood donation: a systematic review. Bull World Health Organ. 2016;94(11):841-9. DOI: 10.2471/ BLT.16.174540 PMID: 27821887

43. Zhang Q, Sun K, Chinazzi M, Pastore Y Piontti A, Dean NE, Rojas DP, et al. Spread of Zika virus in the Americas. Proc Natl Acad Sci USA. 2017;114(22):E4334-43. DOI: 10.1073/ pnas.1620161114 PMID: 28442561

\section{License and copyright}

This is an open-access article distributed under the terms of the Creative Commons Attribution (CC BY 4.0) Licence. You may share and adapt the material, but must give appropriate credit to the source, provide a link to the licence, and indicate if changes were made.

This article is copyright of the authors, 2017. 